\title{
A fila da merenda escolar no Ensino Médio: violência e direito alimentar
}

\author{
The school lunch queue in High School: violence and food law \\ La cola de almuerzo escolar en la Escuela Secundaria: violencia y derecho alimentario
}

\section{Resumo}

No âmbito do Programa Nacional de Alimentação Escolar a oferta de refeições e lanches à estudantes nas escolas públicas ocorre por meio da mediação em filas. Estas representam modos de organização social e acesso ao direito à alimentação. Propõe-se analisar as expressões, significados simbólicos e condutas dos estudantes no contexto institucional do cotidiano da fila de oferta da merenda escolar no ensino médio de uma escola da rede pública. Para maior aproximação dessa realidade, faz-se observação participante e complementa-se a análise com narrativas de escolares, profissionais da educação e funcionários da escola, produzidas por meio de redações e entrevistas. A fila é problematizada como um lugar de humilhação, assédio moral, violência sexual e fome. Descreve-se as experiências desses escolares em situação de fome e insegurança alimentar diante de atos de violência de gênero manifesta implícita, velada, simbólica. Conclui-se a fila da merenda como um lugar contraditório à prática pedagógica humanista e ao direito à alimentação escolar.

Palavras-chave: Alimentação escolar; Violência; Educação; Ensino fundamental e médio; Segurança alimentar.

\begin{abstract}
Within the scope of the National School Feeding Program, the provision of meals and snacks to students in public schools occurs through mediation in queues. These represent modes of social organization and access to the right to food. It is proposed to analyze the expressions, symbolic meanings, and behavior of students in the institutional context of the daily routine of the line of school lunches offered in high school in a public school. To get closer to this reality, participant observation is carried out and the analysis is complemented with narratives from students, education professionals and school employees, produced through essays and interviews. The queue is problematized as a place of humiliation, bullying, sexual violence and hunger. It describes the experiences of these students in situations of hunger and food insecurity in the face of acts of implicit, veiled, symbolic gender violence. The lunch line is concluded as a contradictory place to humanist pedagogical practice and the right to school meals.
\end{abstract}

Keywords: School feeding; Violence; Education; Education primary and secondary; Food security.

\section{Resumen}

En el marco del Programa Nacional de Alimentación Escolar, la provisión de alimentos y bebidas a los alumnos de las escuelas públicas se realiza mediante mediación en colas. Estos representan modos de organización social y acceso al derecho a la alimentación. Se propone analizar las expresiones, significados simbólicos y comportamientos de los estudiantes en el contexto institucional de la rutina diaria de la línea de almuerzos escolares que se ofrecen en el bachillerato en una escuela pública. Para acercarse a esta realidad, se realiza la observación participante y el análisis se complementa con narrativas de estudiantes, profesionales de la educación y empleados de la escuela, producidas a través de ensayos y entrevistas. La cola se problematiza como un lugar de humillación, acoso, violencia sexual y hambre. Se describen las vivencias de estas alumnas en situación de hambre e inseguridad alimentaria ante actos de violencia de género manifiesta, implícita, velada, simbólica. La cola del almuerzo se concluye como un lugar contradictorio con la práctica pedagógica humanística y el derecho a la alimentación escolar.

Palabras clave: Alimentación escolar; Violencia; Educación; Educación primaria y secundaria; Seguridad Alimentaria. 


\section{Introdução}

Trata-se de analisar a conduta dos estudantes no contexto institucional do cotidiano da fila de distribuição da merenda escolar no ensino médio da rede pública da cidade de Salvador. Focaliza-se a fila enquanto um instrumento pedagógico de organização para o consumo da alimentação do Programa Nacional de Alimentação Escolar (PNAE), direito do escolar, concedido pela instituição. Essa dupla função se constitui um direito para a organização e o funcionamento dessa política social, a qual se afirma como uma conquista histórica para os estudantes brasileiros ocorrida desde a década de 1970 até os dias atuais(Lei 11.947, 2009; Peixinho, 2013).

Por meio do acesso à alimentação nas atividades de ensino, os estudantes das escolas públicas têm oferta de refeições que contribuem para o desenvolvimento físico e mental, aprendizagem, rendimento escolar e formação de hábitos alimentares saudáveis (Lei 11.947, 2009; Ministério da Educação, 2020). O PNAE garante uma complementação alimentar diária à quarenta milhões de estudantes, no entanto, para muitos desses representa a única refeição consumida no dia (Amorim et al., 2020). Na cidade do Salvador, usufruem do PNAE, escolares das camadas populares sendo majoritariamente pretos ou pardos, segundo censo escolar do Instituto Nacional de Estudos e Pesquisas Educacionais Anísio Teixeira(INEP) (INEP,2020).

Os usuários do PNAE são sujeitos que vivenciam vulnerabilidades sociais decorrentes da extrema desigualdade social do país. Como membros das camadas populares a fome crônica é revelada a cada dia na competição pela refeição ofertada, em uma condição antipedagógica na qual se inscreve a organização da formação da fila. Assim o presente estudo, focaliza a fila da merenda como um problema social a ser analisado.

Toma-se como referência neste estudo, a definição de filla associada a "fileira de pessoas [...] por ordem cronológica de chegada, [...] a qualquer estabelecimento, onde haja grande afluência de interesse" (Ferreira et al., 2009, p.896). Nesse sentido, o conceito adscrito refere-se a fila como forma de organização humana, circunscrita em geral, a baixa capacidade de oferta e a alta quantidade de demanda. Essa análise aproxima-se das noções originárias à teoria da fila (Iglesias, 2007; Iglesias \& Günther, 2009).

São amplamente reconhecidas as modalidades de filas e se constituem em diversas formas de organização: presencial, não presencial, virtual, invisível, fila única ou múltiplas, preferenciais, com senhas. O caráter ubíquo da fila originou múltiplas abordagens teóricas. Ressalta-se maior difusão nos processos de planejamento da vida urbana, relativos ao ordenamento, disciplina, tempo de espera, gerenciamento do atendimento (Iglesias, 2007; Iglesias \& Günther, 2009). Também, focaliza-se as concepções que tratam as relações interpessoais e interação do comportamento dos indivíduos na fila, à espera por bens e serviços, conforme estudos da psicologia social (Iglesias, 2007; Iglesias\& Günther, 2009).

No presente artigo, tem-se contribuições da sociologia para análise da fila como "fato social total", Marcel Mauss (2003), a fim de evidenciar as tensões e múltiplas dimensões constitutivas (religiosas, jurídicas, étnicas, econômicas, morais, pedagógicas e de saúde). Para tanto, considera-se à guisa da análise empírica as perspectivas teóricas de Goffman (1982) sobre as interações sociais em espaços públicos e as antropológicas nos estudos de Cardoso de Oliveira (2018), que ensejam fenômenos relacionados às interações sociais e condutas de grupos.

Nesse contexto, a fila constitui-se oportuna para descrever e interpretar como as dinâmicas envolvidas na ação da distribuição da alimentação do PNAE podem ser compreendidas pelos estudantes em sua interação com outros agentes da escola (diretores, professores, funcionários da escola), e como podem orientar os modos de agir observados e/ ou narrados pelos indivíduos acerca do direito ou não direito à alimentação no PNAE.

É importante lembrar que a alimentação escolar foi considerada como insegura do ponto de vista alimentar e nutricional aos estudantes em 2015 (Bastos et al., 2015). No ensino médio, os escolares reconhecem a insuficiência da alimentação, os baixos recursos para a produção de refeições no PNAE e a insegurança alimentar de alguns colegas e suas famílias, conforme constatações apresentadas neste presente estudo. 
A exclusão econômica e a fragmentação social são fatores que podem motivar práticas violentas inclusive no ambiente escolar (Tavares dos Santos \& Machado, 2019). Neste sentido, pressupõe-se que no âmbito da escola pública, formase um palco de agressões diversas e atos de violência. A violência escolar engloba a sofrimento físico e mental: castigos corporais; violência psicológica, incluindo abuso verbal; violência sexual incluindo estupro e assédio; bullying e cyberbullying, segundo relatório sobre a situação mundial de violência escolar e bullying da Organização das Nações Unidas para a Educação, a Ciência e a Cultura (UNESCO). (Unesco, 2019, p. 8).

Considera-se como aspectos possíveis para análise nesta pesquisa a hostilidade ou humilhação entre estudantes e funcionários da escola. A noção de humilhação, vale ressaltar, está relacionada a um tipo de violência e se refere a todo "uso de rebaixamento de uma pessoa ou grupo, um processo de sujeição que abala e destrói o orgulho, honra e dignidade" (Decca, 2005, p.108), e pode desencadear processos psicológicos e sociais gerados pela ofensa e rebaixamento da estima (Decca, 2005). Incluem-se entre os atos de humilhação a agressão moral, física e o constrangimento (Instituto Vladmir Herzog, 2015). Essas noções se opõem ao direito humano à alimentação, especialmente por ferir a dignidade da pessoa e discriminá-las como sujeitos de direito a alimentarem-se na escola. Nesse lugar onde também se observa o descaso das autoridades em relação à violência na fila do PNAE.

Para Ansart (2005, p.15), "a situação de humilhação é racional e ausente de reciprocidade". Vale salientar, que as condutas de humilhação na alimentação escolar não são estudadas amplamente, embora relevante, possivelmente por ser específico de um dado contexto social, aqui apresentado como um dos resultados desse estudo etnográfico. Para melhor compreender a fila na merenda escolar como problema serão apresentados os modos como os indivíduos agem e reagem às formas de violências.

Nas escolas públicas, a fila da merenda, pode constituir-se como espaço de disputas das refeições entre estudantes, professores e funcionários administrativos principalmente em dias de cardápios como feijão tropeiro, frango com macarrão, cachorro quente. Situação análoga foi documentada por Bezerra (2009), no Ceará. Esse tipo de competição acirrada pela comida, é um paradoxo às concepções do PNAE enquanto prática pedagógica para a educação alimentar e nutricional (Lei 11947, 2009; Cervato-Mancuso et al., 2013; Ottoni et al., 2019).

Nessa observância, compreende-se o fenômeno da fila constituído de sinais, linguagem verbal, não verbal, cultural, textual. Trata-se, pois, de uma espécie de semiologia de códigos de signos aleatórios e intencionais complementares à interpretação de significados da cultura alimentar nesse contexto pesquisado.

Na literatura se encontra referências ao assédio moral semanticamente similar à humilhação em um determinado contexto do trabalho. Sobre isto, recorre-se ao estudo de Hirigoyen (2006) e Vasconcelos (2015), para caracterizar a modalidade de assédio moral, sua origem e os meios de agressão utilizados (textos, gestos, atitudes). O assediador fala e faz condutas abusivas que trazem dano à pessoa. $\mathrm{O}$ assediado sofre com o abuso do poder e a manipulação. $\mathrm{O}$ assédio moral é uma modalidade de agressão psicológica (Vasconcelos, 2015; Unesco, 2019). No ambiente de distribuição da alimentação escolar, ao introduzir a problemática da fila no PNAE, as microviolências, como exemplo, gritos, uso de termos pejorativos, recusa de atenção às demandas dos estudantes (Roché, 2000; Abramovay, 2012, p. 47), com atos humilhantes, chama atenção durante as interações existentes entre a direção e funcionários da escola e os estudantes. Nesse contexto, os atos de violência ocorrem especificamente pelo caráter constrangedor dos direitos humanos e contrário ao conjunto de ações pedagógicas.

Outro fenômeno a ser considerado durante as interações sociais, no contexto da distribuição da alimentação escolar, na fila da merenda, é a violência sexual de gênero, identidade ou expressão, conforme problematização deste estudo. Vale dizer que a importunação se torna assédio, diante da insistência do comportamento indesejado do assediador (Freire \& Gualande, 2016; Unesco, 2019; Vasconcelos, 2015). Na escola estudada, este problema afeta de forma desigual meninas e 
meninos. As meninas, na realidade adolescentes, se sentem acuadas, quase sempre por um grupo de jovens agressivos. O bullying sexual no meio da fila e da fome se assemelha a uma situação sem saída para muitas que precisam se alimentar.

O exame dos contrastes e interações na fila, as problemáticas geradas pela aglutinação na espera e distribuição da alimentação são aqui descritas no espaço social do PNAE. Intenciona-se, abrir uma discussão, tornando-a oportuna para compreender as consequências negativas geradas nos estudantes, e ainda pouco conhecidas na literatura. Importante nesse aspecto é a apreensão pelos escolares, merendeiras, funcionários e profissionais da educação, sobre os aspectos subjetivos negativos originários desse processo. Com isso, indaga-se, como é a experiência de ser estudante na fila da merenda? Há aspectos implícitos sobre as subjetividades limitadoras, ou não, do alcance de direitos humanos à alimentação no PNAE e sobre a natureza das atitudes dos agentes no espaço alimentar, sobretudo, no exato momento da fila. Nesse lugar, o presente estudo objetiva analisar os significados do direito à alimentação escolar conjecturando expressões e condutas dos estudantes no contexto institucional do cotidiano da fila de distribuição da merenda escolar no ensino médio de uma escola da rede pública da cidade de Salvador.

\section{Aspectos Metodológicos}

Esse artigo é resultado de uma pesquisa com abordagem qualitativa fundamentada nos princípios da etnografia e desenvolvida em uma escola pública de ensino médio, localizada em um bairro central de classe média alta, da cidade de Salvador.

A escola fundada em 1994 apresenta uma edificação de três pavimentos, trinta salas de aula, um elevador, uma biblioteca e refeitório desativados, uma sala de professores, uma sala da direção, uma sala da vice- direção, uma secretaria, uma sala de coordenação, uma cozinha, três depósitos, seis banheiros, dois auditórios, uma quadra de esportes, uma sala de arquivo, dois laboratórios, sendo um deles de informática e uma sala destinada à banda da escola.

Em 2019, estavam matriculados aproximadamente mil e duzentos alunos do ensino médio e profissionalizante e Educação de Jovens e Adultos (EJA), distribuídos em três turnos, sendo o matutino o maior, seguindo do vespertino e noturno respectivamente. Apesar da citada localização, atende estudantes oriundos dos bairros da periferia da cidade, tendo como perfil majoritariamente estudantes pretos e pardos. Diariamente, os estudantes são servidos pela alimentação escolar, composta predominantemente por preparações como: suco com biscoito, mingau, arroz com frango, feijão tropeiro, frutas, cachorro quente.

As motivações para este trabalho, seguem estudos de Laplantine (2004) em relação à descrição das experiências, situações e sensações vividas na realidade social. Nesse universo de observação, verificam-se situações na distribuição e consumo da alimentação do PNAE, nas dependências externas e internas da cozinha escolar e no cotidiano das filas da merenda durante o período letivo de maio de 2018 a novembro de 2019.

Durante a pesquisa de campo, a observação foi realizada no pátio da escola no momento de formação das filas. As filas formadas antes e durante o processo de distribuição das refeições têm características distintas. Algumas, múltiplas, separadas por sexo, produzem aglomerações na porta de um único guichê para atendimento (o portão da cozinha). $\mathrm{O}$ atendimento depende da ordem de chegada, sem haver critério de prioridade para as raras gestantes.

Os métodos da investigação da fila envolveram a observação participante e a análise de narrativas (entrevistas semiestruturadas) (Minayo et al., 2016). A observação do cotidiano em momentos distintos dos processos de organização da alimentação escolar foi essencial para a aproximação dos estudantes (sendo um total de dez os que aceitaram falar aberta e sigilosamente sobre os problemas na fila da merenda). Além de conversas em grupos de dois a três alunos em momentos distintos da distribuição da alimentação escolar, dentro e fora da escola. 
Vale mencionar que o método de observação sucessiva da fila da merenda possibilitou um olhar atento e questionador (Laplantine, 2004). Conforme aplicação da técnica, foi realizado um estudo minucioso sobre o processo de distribuição das refeições, com posterior anotações no diário de campo. Ademais, houve momentos de interação com o diretor, vice-diretor, merendeiras, professores e estudantes em entrevistas gravadas sobre o PNAE como um direito alimentar e seu funcionamento na escola. Assim, gerou-se um conteúdo em que se distinguem contradições e similitudes em relação aos comportamentos dos sujeitos na fila, desafios durante o consumo e revelações imprevisíveis sobre a alimentação do PNAE.

Sublinha-se a sensibilidade do observador na produção e descrição sobre o universo circunscrito ao PNAE. A experiência, como nutricionista, em circunstâncias anteriores permitiu o exame das condições concretas da execução do programa e tornou possível compreender as regras e os procedimentos dos agentes, em sua organização para o consumo da alimentação escolar, como também, (re)interpretar as ações geradas a partir da interação com os membros do grupo da comunidade escolar.

As entrevistas semiestruturadas foram realizadas tendo com interlocutores: duas merendeiras, três professoras, duas coordenadoras, três professores da direção e dez estudantes, os quais tiveram suas identidades preservadas por meio de nomes fictícios. Essas técnicas reunidas resultaram um material que foi analisado organizando-se um conteúdo que relacionou questões apreendidas nos momentos da distribuição da merenda, como mencionado, tais como gestos e outras expressões representativas das interações no cotidiano da fila.

A análise dessas informações seguiu-se em três etapas, de acordo com os passos sugeridos por Minayo e colaboradores (2016), a primeira consistiu na transcrição das entrevistas na íntegra, em seguida foi realizada uma leitura minuciosa, e a terceira, a categorização das informações e significantes, tais como se percebeu no grupo de escolares: "medo, mal-estar, empurrão, aperto, fome, necessidade".

Para interpretação foram utilizados como referência estudos de Geertz (1989) e hermenêutica dialética, de Maria Cecilia Minayo (2003). Analisou-se palavras, ações, inter-relações, grupos, linguagem, símbolos (Minayo et al., 2016). Agregou-se a essa análise, a identificação de etnométodos (Coulon, 1995, 2008, 2017) inscritos no microfenômeno social de organização da fila na escola, sendo alguns utilizados na análise.

Esse recorte analítico e interpretativo proposto permitiu compreender os conflitos, códigos, regras e formas simbólicas expressas pelos interlocutores em diferentes situações referenciadas pela fila da merenda.

A pesquisa foi aprovada pelo comitê de ética em pesquisa da Escola de Nutrição da Universidade Federal da Bahia.

\section{Resultados e Discussão}

\subsection{A organização da fila da merenda}

Os critérios para o atendimento na fila da merenda não se encontram institucionalizados. Apesar de existirem regras tácitas, como quem chega primeiro é logo atendido, há também regras constitutivas para tentativa de organização como: separação por gênero, uso de fardas pelos estudantes a fim de limitar o consumo dos matriculados, com a presença de um funcionário. Entretanto, as disputas se tornam acirradas, no turno da manhã, com aproximadamente quatrocentos estudantes, ou mais, aglomerados em um estreito pátio. Como a organização da fila não se constitui objeto da prática pedagógica, exceto para atitudes punitivas, adiante discutidas, não há como ordenar uma fileira. Os estudantes sentem desconfiança e receio da perda do alimento, resultando em atitudes brutais pela competição para garantir a comida. É, o que ocorre em dias em que a merenda apresenta um cardápio de maior preferência como feijão tropeiro ou sanduiche de "cachorro quente". Empurrões, chutes e socos fazem parte da cena comum de conflito, abuso físico e psíquico ao lado da indiferença dos gestores. A análise situacional articulada ao PNAE mostra um processo antipedagógico e brutal. 
A fila se distribui em todo o espaço disponível no andar térreo da escola, no pátio junto à imagem de um santo católico, ao lado do refeitório em reforma e cercado por grades de ferro que delimitam o lugar disponível para os alunos. Com a aproximação do horário do intervalo, os estudantes se aglutinam. Na medida que o tempo avança, amplia-se a fila e aumenta o nível de agitação e ansiedade daqueles que aguardam a distribuição da alimentação escolar pelas merendeiras. Com isso, formam-se várias camadas na auto-organização da fila da merenda. Há os que chegam mais cedo e garantem os primeiros atendimentos, evidentemente deixando de frequentar aulas. Há privilégios para os professores e funcionários da escola que têm preferência ao acesso à merenda, esta que deveria ser prioritariamente destinada aos escolares (Lei 11947, 2009; Ministério da Educação, 2020). "Ruim é o professor comer antes de nós. Quando a merenda é boa, elas levam para os professores primeiro" (Antônia, 18 anos). Nesse conjunto irregular, é possível notar a desigualdade nas relações de poder entre estudantes e outros atores.

Na perspectiva da educação, a alimentação pode constituir-se como tema gerador das atividades pedagógicas em discussões dos aspectos relacionados à saúde, autocuidado e promoção da alimentação saudável (Costa et al., 2001; Lei 11947, 2009; Ministério da Educação, 2020). O exame de alguns estudos sobre o programa de alimentação escolar e aprendizagem revelaram o carácter pedagógico da alimentação escolar (Costa et al., 2001; Barbosa et al., 2013; Jones \& Zidenberg-Cherr, 2015; Silva et al., 2018). Constatou-se uma predominância de conteúdos educativos centrados nos currículos, voltados para disciplinas e com foco no público da educação primária (Silva et al., 2018; Jones \& Zidenberg-Cherr, 2015). Entretanto, a organização da fila encontra-se fora das definições político-pedagógicas e alimentares do PNAE e nesta anomia, no espaço da escola, emergem modalidades de violências na disputa cotidiana pelo alimento.

\subsection{Experiência da fila da merenda para os alunos}

A observação direta da alimentação na escola permitiu verificar diferenças e semelhanças nas filas formadas. Para os estudantes, a fila da merenda são sempre iguais. Os sentidos são os mesmos, como impaciência, o sofrimento pelos empurrões, tudo se repete, o que muda é o nível de intensidade das reações na fila. As narrativas das estudantes demonstram o tamanho da fila como problema para o consumo da alimentação, “[...] algumas pessoas nem conseguem pegar a merenda, porque a fila é grande" (Vitória, 18 anos), "Pelo fato da grande fila que forma não dá chance de comer direito" (Amanda, 18 anos). Foram observadas situações recorrentes de merenda insuficiente. Essa condição resultava em terrível frustação, continuidade do estado de fome aguda e humilhação.

Para DaMatta e Junqueira (2017), em estudo sobre várias filas urbanas no Rio de Janeiro, mostra que estas são justas quando organizadas, mas em geral, na prática a realidade é de injuria, com aglomeração, fura-filas, privilégios (DaMatta \& Junqueira, 2017). Iniquidades semelhantes foram constatadas na fila da alimentação escolar, quando não atendem ao seu objetivo de organizar o acesso à alimentação por ordem de chegada, além de desconsiderar necessidades especiais de parte de alunos.

Por isso, a rotina de enfileirar-se para obter a refeição, ao tempo em que produz sentidos de satisfação pelo alcance do direito à alimentação e redução da fome, também promove reações negativas, pois, limita o acesso ao PNAE, claramente descrito pela extensão da fila, competição para o consumo entre os próprios estudantes e diversos atos de humilhação (xingamentos, empurrões, assédio etc.) entre eles e por algumas funcionárias que servem as refeições.

Sobre a condição de humilhação, ato de humilhar e sentir-se humilhado, Pierre Azart (2005, p.17) considera estes aspectos "obscuros e de difícil discernimento", sobretudo, por aqueles que sofrem. Conforme testemunhos de alguns estudantes ofendidos com xingamentos, há relatos como: "Me sinto muito mal"; "É horrível"; "Parecem animais".

Também, há modos de ofensas proferidos pela direção da escola conforme descrição seguinte: Em setembro de 2019, era quase nove horas da manhã, quando o aroma do azeite dendê se propagou pelo pátio e áreas contíguas da escola. Na Bahia, 
sobretudo na área do recôncavo e cidade do Salvador, no mês de setembro é habitual homenagear os santos Cosme e Damião (Ibejis no Candomblé) e oferecer caruru (quiabo cozido com dendê e outras iguarias) às crianças e adolescentes. Esse ato sincrético oriundo da fusão entre religiões de matriz africana e católica é o mais importante evento alimentar coletivo da região. Receber um prato de caruru é como reverenciar os santos jovens e agradecer a alegria, a saúde e a vida (Prandi, 2009). Entretanto, nesse dia, os estudantes foram excluídos pela direção da escola de consumir o caruru, apesar de ser produzido na cozinha para ser oferecido aos professores e diretores. Informados, no horário do intervalo, que não haveria distribuição de caruru, nem de qualquer outro tipo de alimentação, os estudantes se sentiram indignados. Os cheiros do dendê em toda a escola deixaram os estudantes com fome e excluídos do consumo desse rito cultural alimentar. Segundo alguns estudantes, foi uma "ofensa" negar caruru e suspender qualquer outra alimentação. Parecia uma injúria cozinhar caruru e não oferecer aos estudantes.

Impedidos do acesso, o cheiro forte da comida estimulava a sensação de fome psicofisiológica agravada pela fome crônica dos que a vivenciam desde a mais tenra idade (Freitas, 2003). Vale lembrar que estímulos sensoriais são usados pela engenharia e marketing sensorial, comumente aplicados pela indústria de fast food para impregnar ambientes e formar hábitos para aumentar o consumo de alimentos (Freitas et al., 2011). Esta impregnação de odores sem a oferta do alimento, adicionado ao significado simbólico do rito cultural, em contexto de vulnerabilidade social dos estudantes, expressa mais uma modalidade de violência verificada na escola onde deveria ter fila para esta esperada oferenda de setembro.

Observaram-se situações em que a suspensão da oferta da merenda escolar ocorreu por motivo de castigo coletivo, em que todos os estudantes foram punidos pela direção pelo descumprimento de regras tácitas da escola. A punição impôs a fome como estratégia pedagógica voltada para restabelecer a ordem e a "docilidade" ou subserviência e silêncio. Em uma situação se verificou a estratégia punitiva com a oferta apenas pipoca como refeição, de modo recorrente por vários dias. Para os escolares essas atitudes dos gestores são injustas, como afirma Antônia, estudante de 18 anos do curso matutino.

Os sentimentos gerados pela humilhação ou ofensa são cercados de simbolismos, sendo insuficientemente declarados nas narrativas, mas percebidos nas entrelinhas, nas faces cerradas em aborrecimento, cabisbaixos, silenciamentos durante as entrevistas. O assédio moral, aqui atribuído como a suspenção da merenda, a negação do caruru, o oferecimento de pipoca como castigo são práticas de agressão psicológica e com consequências físicas para a saúde dos estudantes. Sobre isso, Adad et al. (2020), traduz como os jovens se sentem e os efeitos de conviver com violências semelhantes na casa e na escola.

No mundo do trabalho, a conduta agressiva, contínua e humilhante resulta numa desigualdade de poder em condições para a situação de assédio vertical ou horizontal (Vasconselos, 2015). Nas escolas, os estudos predominantes são sobre o bullying, ou "comportamento agressivo indesejado entre crianças em idade escolar que envolve um desequilíbrio de poder real ou percebido" (Unesco, 2019, p. 8; Nomelini et al., 2020), uma determinada forma de assédio moral entre os estudantes. No entanto, neste caso, o assédio foi verificado verticalmente, a partir da direção da escola como ato punitivo e persistente, pretensamente pedagógico. Essa modalidade de assédio se realiza como algo legítimo, porém manipular o cardápio da merenda escolar como instrumento punitivo implica em consequências nutricionais que podem repercutir na saúde dos alunos, considerando que, para muitos, a merenda escolar representa a única refeição do dia.

Diante de tal declaração de difícil assimilação, é possível constatar que a sonegação da merenda escolar tenha sido uma espécie de tortura para aqueles estudantes que sentiam fome e não tinham uma alternativa alimentar. Mas, os gestores responsáveis não agem com esse propósito, pois se imaginam educando com coerção. Cabe destacar que o tratamento dado pela instituição é característico de atos de humilhação e relaciona-se a perversidade (Decca, 2005, p.116). Conforme exemplificado na narrativa da estudante, ao sinalizar a falta de comida para os alunos em período integral, "é injustiça, aqui é um colégio técnico e tem vários alunos que ficam muito tempo sem ter comida e ficam o dia todo no colégio." (Antônia, 18 anos). Essa ação é um ato de humilhação invisibilizado pela instituição como tal. 
A apropriação indevida do poder constituído pela posição de diretora e a reação dos estudantes é um dos motivos da atenção desse estudo a questão da humilhação e assédio moral. Os estudantes se sentiram agredidos e feridos em sua dignidade, sem reciprocidade. Pierre Ansart (2005, p.18), "descreve a prática de humilhação como uma arma do poder instalado, uma estratégia para docilidade do cidadão".

Nessa situação o abuso de poder proferido pela direção é uma violência física e psicológica, pois além de contribuir com a fome reforça a condição de desigualdade social, encontra-se reproduzida no ambiente escolar.

Importante dizer que os atos de humilhação são inaceitáveis quando se busca o alcance do direito à alimentação na escola. Do mesmo modo, a fila da merenda revela privilégios para professores e funcionários durante o ato de enfileirar-se. Nessa situação, os estudantes se sentem ofendidos, situação que confronta às expectativas da alimentação exclusiva para o escolar. Frente ao contexto, os estudantes são forçados a passividade e silenciamento, condições características da humilhação e formas de assédios (Decca, 2005).

\subsection{A fome e a espera na fila da merenda: fenômeno pedagógico oculto}

Nas filas os indivíduos ordenam as interações durante a espera a partir do princípio "primeiro a chegar é o primeiro a ser atendido" (Freire \& Gualande, 2016, p. 55). Esse princípio contribui para composição inicial da fila da merenda formada pelos estudantes do ensino médio da escola em questão, os quais compartilham a experiência da espera por quarenta a cinquenta minutos para a distribuição da alimentação escolar. Com frequência, os estudantes foram observados antecipando a formação da fila. Sobre os motivos da precipitação da organização, justifica-se Vitória (18 anos), de forma enfática, - "É fome, tia!" Além dela, outros quatro escolares, que aguardavam na fila, informaram maior possibilidade de obter comida, quando se chega antecipadamente, conforme afirma "quem chega tarde, não come!"

A narrativa dos estudantes alude dois indicativos interpretados, a precaução sobre o tempo de espera na fila da merenda e o cuidado em garantir as primeiras porções para minimizar a fome fisiológica. Segundo Vitória (18 anos), "alguns estudantes não tomam café antes de sair de casa". Para Cássia (18 anos), "costumo comer, o que só dá na escola, se não fico com fome." Importante observar que são distintas e particulares as experiências de fome. Como mencionado, no estudo etnográfico sobre a fome em uma comunidade de Salvador, "cada um sente a fome crônica de modo singular com sua própria percepção e constroem significados específicos." (Freitas, 2003).

A fome aparece como significante da disputa na fila, conforme narrativas de alguns estudantes: "quem não tem alimento em casa, sente a fome do momento" (Silvio,18 anos); "não costumo pegar os lanches oferecidos pela escola, só se sentir fome mesmo" (Ricardo, 18 anos); "a questão da fila é complicada de ser entendida, você enfrenta toda a fila e quando chega sua vez não tem comida" (Jurema, 19 anos). O termo fome aparece quase sempre velado nas narrativas e substituído por: “má alimentação e falta de alimentos." No processo interpretativo, ambas as expressões são sentidos da falta de acesso ao alimento.

Para os estudantes, a falta de comida é um problema gerado pela desorganização da distribuição. Entende-se que a espera na fila alude alguns significados, como frustação e fracasso, que combinados produzem sentimentos de indignidade e inferioridade. Segundo DaMatta e Junqueira (2017), a apreensão e espera de atendimento apresentam um elo direto com as dimensões demarcadoras da inferioridade social, pobreza, subalternidades e destituição de direitos.

Também, para os estudantes, as representações da fila "ocultam posicionamentos subalternos e sub-humanos," conforme observação em estudo sobre a fila (DaMatta; Junqueira, 2017, p.36). É possível que esses jovens adolescentes tenham experiências com as filas em transportes públicos e serviços de saúde. Mas no caso específico do PNAE nessa escola, a fila é desorganizada e parece uma luta de resistência contra a fome, pois não há alimentos para todos. Deste ponto de vista, a alimentação para os usuários do PNAE está associada à comida para pobres e carentes(Silva et al., 2018), embora as 
abordagens em documentos oficiais nacionais, sejam contrárias à premissa assistencialista (Lei 11.947, 2009; Ministério da Educação 06, 2020).

Vale dizer que, ainda há alguns privilegiados ou apadrinhados por merendeiras e outros funcionários da escola. Então, a espera na fila é formada por classificações sociais, entre os que tem mais acesso e outros que se ressentem em relação ao tipo de atendimento prestado pelo PNAE nesse lugar.

Observou-se quatro principais tipos de condutas na fila: 1) Há os que chegam cedo, mesmo faltando a sala de aula; 2) os dominadores (aprendizes do crime organizado instalado na escola?) ou os que lutam pela sobrevivência ao reagirem à dificuldade de acesso aos alimentos, são estes considerados os desordeiros na linguagem oficial; 3) os que quase nunca conseguem se alimentar; 4) Os privilegiados que furam a fila, pois fazem parte do grêmio, se aproximam da diretora da escola, ou são amigos de funcionários.

Os estudantes ainda disputam esta alimentação com membros de maior poder na escola como professores e funcionários da secretaria. - "Bora aí, tia! Deixe para mim também." Comenta o estudante na fila da merenda, gesticulando com os ombros. O exame da expressão deixa para mim também e os gestos revelam naquele exato momento da fila uma indicialidade (Coulon, 1995, p. 32). Conforme estudos da etnometodologia, os sentidos e significações superam as palavras ao revelarem ideias como as exemplificadas neste estudo, em que aparece gestos de reprovação quanto a escassez de alimento e indignação pela situação desigual. Esses sentidos são reforçados pelas palavras de Antônia (18 anos), quanto a sua reprovação aos privilégios: "se estiver 20 professores na escola, serão 20 alunos que estão na fila desde 09:00, que não vão merendar, assim vira injustiça".

A espera na fila significa ineficiência da merenda. Para DaMatta e Junqueira (2017), como as pessoas se comportam na fila e quem nela é atendida são definidores da atenção nesses espaços. Deste ponto de vista, ademais da falta de organização da fila do PNAE, soma-se a disputa pelo alimento, conforme descrito pela estudante: "As pessoas não dão direito à outras de comerem, comem rápido e repetem, enquanto outras ficam na espera e não comem, pois acaba a comida" (Amanda,18 anos). Durante a espera na fila da merenda são geradas expectativas sobre a quantidade da alimentação e o cardápio ofertado. Há estudantes que comem os restos dos pratos de outros, e isso ocorre comumente. Não se joga fora os restos de frango, nem de feijão tropeiro, nem o mingau, mas são aproveitados pelo outro colega. Essa é a construção social da cultura de fome no cotidiano da escola. E, há outros que comem, desesperadamente, dois ou três pratos.

Sabe-se que os cardápios no PNAE são preparados para os estudantes do ensino médio, com recursos no valor mínimo de trinta e seis centavos por dia (Ministério da Educação, 2020). Algumas vezes, são distribuídos aos escolares alimentos como: sucos industrializados, pipoca, biscoito, insuficientes para sanar a fome do escolar. Como foi possível notar em campo, nas faces dos estudantes insatisfeitos e desanimados ao depararem-se com atendimento pouco qualificado, ausência de pessoal capacitado, presença de aglomerações, privilégios, numerosos estudantes e disputas são questões reveladoras da fila da merenda e o não atendimento ao direito à alimentação. Desvela-se um fenômeno aparentemente, oculto: o uso do PNAE na realidade dramática da fome e da violência na escola.

\subsection{A fila da merenda e seus conflitos: o uso da merenda escolar como forma de punição}

A violência difusa e presente nos mais remotos espaços da vida social no país (Brasil, 2020) pode estar ali no pátio de uma escola pública no momento da alimentação. O direito de alimentar-se passa, então, por uma contradição entre comer e subordinar-se, comer e manter-se em posição de poder ou não comer. Não há o direito explícito nas regras oficiais da escola, e isso requer dos estudantes o domínio dos códigos e aprendizagem de rituais determinados no dia-dia da distribuição do PNAE.

Surge um contraponto ao conjugar direito à alimentação e fila da merenda. Pois, foi constatado a violação dos princípios do direito à alimentação, com a desigualdade e a discriminação ao acesso à alimentação, ausente universalidade e 
garantia de dignidade na oferta, todas essas ações são contrárias na prática cotidiana da escola de Salvador. Contrárias ao que Siqueira e colaboradores (2014), expressam como Direito humano à alimentação na legislação do PNAE (Lei 11.947, 2009; Ministério da Educação, 2020).

$\mathrm{Na}$ prática, compartilham gostos e valores, os quais são estruturantes do mundo ordinário em que vivem, e tem correspondências com o ambiente escolar. Entretanto, há mais questões a serem observadas. Uns estudantes acuados não aguentam participar das atitudes agressivas de um grupo contra outros, no momento da distribuição das refeições, a exemplo da disputa com agressão física em dias de "cachorro quente", cardápio atraente para os adolescentes. Apesar da alegria por um cardápio desejado há tanta disputa que a predominância de contentamento se esvai. Muitos não conseguem se alimentar.

As merendeiras receavam distribuir a refeição por causa de ameaças que recebiam de alguns alunos. Também, foram frequentes os relatos dos escolares sobre o não consumo de refeições com alta aceitabilidade como feijão tropeiro, cachorro quente, entre outras preferenciais. Não conseguiram alcançar a distribuição, pela aglomeração, gritos e disputas. Nesse sentido, a insegurança alimentar e nutricional parece duplicar-se tanto pela descontinuidade das refeições, quanto pelas dificuldades de acesso.

Como observado, a violência sexual ocorre no espaço da fila da merenda em momentos de aglomerações diárias. Num olhar mais atento da pesquisadora, nota-se que alguns rapazes pareciam empurrar outros nas paredes e grades e usam de violência verbal, com intimidação de natureza sexual, contato corporal indesejado e coerção (Unesco, 2019, p.15), entre meninos e meninas. A observação direta nesse espaço de alimentação permitiu identificar preocupações não devidamente exteriorizadas nas narrativas. Ao compartilhar essas preocupações com algumas estudantes, houve sinais de negação e silenciamento, conforme esperado. Estão apavoradas.

Segundo relatório Unesco (2019), as vítimas de violência sexual com frequência sentem medo de serem humilhadas, estigmatizadas ou sofrerem novas agressões, por isso, o silenciamento resulta na invisibilização dessa violência escolar (Tavares dos Santos \& Machado, 2019; Unesco, 2019;). Ainda assim, não há como deixar de registrar a omissão dos responsáveis pela instituição, como se fechassem os olhos e ouvidos para se distanciarem dos escolares. Enquanto isso, tensões e estresse, como consequências das aglomerações, dos privilégios e da pouca organização na fila marcam o PNAE nessa escola. Desse modo, a distribuição da alimentação torna-se o momento propício para as práticas violentas que podem atingir a integridade psíquica de estudantes. Observa-se uma retração da participação das jovens, como se esquivassem dos agressores, como descrito antes. A cena se repete diariamente sobretudo a situação análoga a importunação sexual (Lei no 13.718, 2018), conforme vista nos transportes públicos, uma prática machista e brutal.

Assim, observa-se tumultos intencionais que desrespeitam a hierarquia da fila provocando tensões e empurrões. Essa (des)organização resulta no desequilíbrio da distribuição da alimentação, pois, os rapazes permanecem na frente atrapalhando o processo de distribuição e comprometendo o atendimento ao grupo feminino, embora, este seja a maioria na escola. Esta é a organização que os estudantes conhecem. As raras gestantes não têm prioridade na fila e os garotos trans se encontram perdidos entre as fileiras. Nos bastidores, as meninas em depressão, em rodas de conversa puderam abrir-se sobre suas obesidades e outros conflitos. Nesse instante, a participação da pesquisadora transcende a investigação.

Para Michel Misse (2005), a linguagem cotidiana com expressões linguísticas associadas ao gênero, reforçam e reproduzem lógicas de submissão e violência. Semelhante ao que ocorre na fila da merenda escolar, em que, nem mesmo a separação por gênero favorece o feminino ao acesso à refeição. Isso porque os rapazes se aglomeram e limitam fisicamente a proximidade das adolescentes à recepção da refeição. Há de fato, uma violação do gênero.

Importante assinalar que os direitos, conforme nos apresenta Pérez Luño, (2001, p. 48) são "um conjunto de faculdades e instituições", ou seja, na ausência ou violação de um direito humano significa que todos outros direitos podem ter dificuldades de serem efetivados, a exemplo do direito à alimentação observado. 


\section{Considerações Finais}

A escola estudada não imprime coerência ao PNAE e vice-versa. A fila escapa das mãos dos gestores da escola e a alimentação passa a ser uma necessidade isolada da educação. Um dos efeitos pedagógicos perversos se encontra na fila a qual limita o estudante a se organizar para o acesso ao alimento naquele estreito espaço do pátio, para centenas de alunos e alunas expostos e vulneráveis.

Assim, a partir dos assuntos analisados, têm-se elementos para finalizar algumas considerações possíveis acerca da origem das situações descritas e as justificativas das ações dos profissionais da educação, funcionários da escola e dos estudantes, as quais se conectam às noções de humilhação, assédio, violência psicológica e violência sexual.

Provar a relação de causa (agressão) e consequência (sofrimento da vítima) não é simples, sobretudo, quando as relações de poder são institucionais. Desta maneira, esta etnografia descortina problemas em relação à fila, antes interpretada apenas como aglomeração e algazarra de jovens. Este texto denuncia formas de acesso ao PNAE nesta escola onde há formas de resistências contra a fome com violências e medos. Não há casos de renúncia à tentativa de acesso ao alimento. Os poucos que recuaram retornaram em outros dias para o confronto ou a subordinação do acesso. Foram muitos os sinais emitidos, silenciamentos, gestos e palavras proferidos nos momentos de agitação emocional, conforme reafirmado em algumas narrativas durante as interações dos estudantes na fila do PNAE.

Frente à estas situações os estudantes reagiram. Alguns, ignoravam, pois a fome, os impelia a esperar na fila, mesmo contrariando sua dignidade, tantas vezes a escutar xingamentos, empurrões propositais etc. Para outros, evitar a fila foi com a marmita de refeição de casa, mesmo sem infraestrutura (falta mesa, cadeiras, refeitório, forno de microondas, pias para higienização). No contexto escolar, ainda que haja respaldo legal para inibir práticas violentas a escola continua produzindo subjetividades envolvidas na questão e desafios para uma pedagogia de desconstrução dessas práticas. As atitudes oriundas de atos de humilhação e assédio moral, embora admitidas pelos agressores são compreendidas como formas de coesão e legitimação da autoridade perversa diante da inexistência de políticas pedagógicas para esse espaço escolar. Com isso, propiciam-se impensáveis atitudes orientadas por condutas de (des) humanização ou violência e da exploração da fome como motivo da disputa pelo poder com o alimento.

Finalmente, quanto o potencial pedagógico da fila no espaço escolar, a ênfase deveria ser na sua organização para o acesso à alimentação como um Direito e uma oportunidade de formação ético-política do aluno. Com isso, é necessário desconstruir os aspectos dramáticos verificados nas condições de promoção da violência e assédios.

Vale considerar que todos os funcionários da escola devem exercer o seu trabalho na perspectiva de promoção de práticas pedagógicas e institucionais em consonância aos direitos humanos, especialmente o direito à educação e alimentação.

Nesse panorama, ainda que tenha merenda na escola, a fila deve representar um meio para que o estudante do ensino médio alcance os seus direitos e não represente uma tragédia pedagógica. Desta forma, como trabalhos futuros sugere-se mais análise da fila e suas representações para os estudantes, utilizando-se de mecanismos que potencializem o protagonismo dos jovens, além do combate as situações de violências no âmbito escolar.

\section{Referências}

Abramovay, M. et al. (2015). Abramovay, Miriam et al. (2012) Conversando sobre violência e convivência nas escolas. FLASCO-Brasil, Organização dos Estados Ibero-Americanos (OEI), MEC. http://flacso.redelivre.org.br/files/2015/03/conversando_sobre_violencia.pdf.

Adad, S. J. H. C, Santos, V. N, \& Silva, K. S. (2021). Juventudes, violência e convivência na escola: Uma pesquisa sociopoética. Research, Society and Development,10(8), 1-9. http://dx.doi.org/10.33448/rsd-v10i8.17048.

Amorim, A. C. B., Ribeiro-Junior, J. R. S. \& Bandoni, D. H. (2020). Programa nacional de alimentação escolar: estratégias para enfrentar a insegurança alimentar durante e após a COVID-19. Rev. Adm. Pública, 54(4),1134-1145. https://doi.org/10.1590/0034-761220200349.

Ansart, Pierre. (2015). As humilhações políticas. In I. Marson \& M. Naxara (Org.). Sobre a humilhação, sentimentos, gestos palavras. EDUFU. 
Barbosa, N.V. S., Machado, N. M. V., Soares, M. C. V. Pinto, A. R. R. (2013). Alimentação na escola e autonomia - desafios e possibilidades. Cien. Saúde Colet.18(4), 937-945. https://doi.org/10.1590/S1413-81232013000400005TO.

Bastos, F. A. P., Cardoso, J. \& Santos, S. M. C. (2015). Diagnóstico da Segurança Alimentar e Nutricional do Estado da Bahia. Grupo Governamental de Segurança Alimentar e Nutricional [GGSAN] Conselho Nacional de Segurança Alimentar e Nutricional[CONSEA], EGBA

Bezerra, J. A. B. (2009). Alimentação e escola: significados e implicações curriculares da merenda escolar. Revista Brasileira de Educação, 14, $103-115$. https://www.scielo.br/pdf/rbedu/v14n40/v14n40a09.pdf.

Brasil. (2020). Atlas da violência 2020. Rio de Janeiro, São Paulo: Instituto de Pesquisa Econômica Aplicada, Fórum Brasileiro de Segurança Pública. https://www.ipea.gov.br/atlasviolencia

Cardoso de Oliveira, L. R. (2018). O ofício do antropólogo, ou como desvendar evidências simbólicas. Anuário Antropológico, 32(1), 9-30. https://periodicos.unb.br/index.php/anuarioantropologico/article/view/6944

Cervato-Mancuso, A. M., Westphal, M. F., Araki, E. L., \& Bógus, C. M. (2013). O papel da alimentação escolar na formação dos hábitos alimentares. Revista Paulista de Pediatria, 31(3), 324-330. https://doi.org/10.1590/S0103-05822013000300008.

Costa, E. Q. ; Ribeiro, V. M. B., \& Ribeiro, E. C. O. (2001).Programa de alimentação escolar: espaço de aprendizagem e produção de conhecimento. Rev. Nutr, 14(3), 225-229. https://doi.org/10.1590/S1415-52732001000300009.

Coulon, A. (1995). Etnometodologia. Vozes.

Coulon, A. (2008). A condição de Estudante a entrada na Vida universitária. Edufba.

Coulon, A. (2017). Etnometodologia e Educação. Cortez.

Decca, E. S. (2005). Sobre a humilhação, sentimentos, gestos palavras. In I. Marson \& M. Naxara. Sobre a Humilhação. EDUFU.

DaMatta, R., \& Junqueira, A. (2017). Fila e Democracia. Rocco.

Ferreira, A. B. H., Ferreira, M. B., \& Anjos, M. (2009). Novo dicionário Aurélio da Língua Portuguesa. (4a ed.). Positivo.

Freire, J. \& Gualande, A. (2016). Tensões e conflitos no transporte coletivo de Campos dos Goytacazes: Uma sociologia das filas de espera. RBSE. Revista Brasileira de Sociologia Da Emocao, 15(45). http://search.proquest.com/docview/2132273926/

Freitas, M. C. S. (2003). Agonia da Fome. EDUFBAFIOCRUZ.

Freitas, M. C. S, Pena, P. G. L. \& Fontes, G. A. V. (2011). Hábitos alimentares e os sentidos do comer. In R.W. Díez-Garcia \& A. M. Cervato-Mancuso (Org.), Mudanças alimentares e educação nutricional. Guanabara Koogan, 35-42.

Geertz, C. (1989). A interpretação das culturas. Guanabara Koogan.

Goffman, E. (1982). Estigma: nota sobre a manipulação da identidade deteriorada. Zahar editores.

Hirigoyen, M. F. (2006). Assédio moral: a violência perversa no cotidiano. (8a ed.). Bertrand Brasil.

Iglesias, F. (2007). Comportamentos em filas de espera: Uma abordagem multimétodos. [Tese Doutorado em Psicologia]. Universidade de Brasília.

Iglesias, F. \& Günther, H. (2009). A espera na vida urbana: Uma análise psicossocial das filas. Psicologia em Estudo, 14(3), 537-545. https://doi.org/10.1590/S1413-73722009000300015.

Instituto Vladimir Herzog. (2015) Respeito e humilhação educação e direitos humanos. .34. Instituto Vladimir Herzog.

Jones, A. M., Zidenberg-Cherr, S.(2015). Exploring nutrition education resources and barriers, and nutrition knowledge in teachers in California. J Nutr Educ Behav. 47(2), 162-9.https://doi.org/10.1016/j.jneb.2014.06.011.

Laplantine, F. (2004). A descrição etnográfica [La Description Ethnographique]. Terceira Margem.

Lei n. 11.947, de 16 de junho de 2009. (2009). Dispõe sobre o atendimento da alimentação escolar e do Programa Dinheiro Direto na Escola aos alunos da educação básica; altera as Leis n 10.880 , de 9 de junho de 2004, 11.273, de 6 de fevereiro de 2006, 11.507, de 20 de julho de 2007; revoga dispositivos da Medida Provisória n n $^{2} .178-36$, de 24 de agosto de 2001, e a Lei nº 8.913, de 12 de julho de 1994; e dá outras providências

Lei $n^{\circ} 13.718$, de 24 de setembro de 2018. (2018). Altera o Decreto-Lei $\mathrm{n}^{\circ} 2.848$, de 7 de dezembro de 1940 (Código Penal), para tipificar os crimes de importunação sexual e de divulgação de cena de estupro, tornar pública incondicionada a natureza da ação penal dos crimes contra a liberdade sexual e dos crimes sexuais contra vulnerável, estabelecer causas de aumento de pena para esses crimes e definir como causas de aumento de pena o estupro coletivo e o estupro corretivo; e revoga dispositivo do Decreto-Lei n n $^{3.688}$, de 3 de outubro de 1941 (Lei das Contravenções Penais). Brasília: Presidência da República, [2018]. http://www.planalto.gov.br/ccivil_03/_ato2015-2018/2018/lei/L13718.htm.

Mauss, M. (2003). Ensaio sobre a dádiva, forma e razão da troca nas sociedades arcaicas. In M. Mauss. Sociologia e antropologia. (2.ed. pp 183-314). São Paulo: Cosac \& Naify.

Minayo, M. C. S. (org.); Deslandes, S. F. \& Gomes, R.(2016). Pesquisa Social: Teoria, método e criatividade. Vozes

Minayo, M C S. (2003). Hermenêutica: Dialética como caminho do pensamento social. In: M.C.S, Minayo; S.F. Deslandes, (Org). Caminhos do pensamento: 
Research, Society and Development, v. 10, n. 15, e515101523197, 2021

(CC BY 4.0) | ISSN 2525-3409 | DOI: http://dx.doi.org/10.33448/rsd-v10i15.23197

epistemologia e método. Rio de Jsneiro: Fiocruz.

Ministério da Educação (2020). Resolução ${ }^{\circ}$ 06, de 08 de maio de 2020. Dispõe sobre o atendimento da alimentação escolar aos alunos da educação básica no âmbito do programa nacional de alimentação escolar - pnae. Diário oficial da união. https://www.fnde.gov.br/index.php/acesso-ainformacao/institucional/legislacao/item/13511-resolução-nº-6,-de-08-de-maio-de-2020.

Misse, M. (2005). O estigma do passivo sexual: um símbolo de estigma no discurso cotidiano. O Núcleo de Estudos da Cidadania, Conflito e Violência Urbana (IFCS-UFRJ). (3 ed.). São Paulo:NECVU /BOOKLIN.

Nomelini, Q. S. S, Cunha, N. S. S, Fernandes, R. M, Oliveira, R. R, Santos, C. C. R, \& Aguena, M. S. (2020). Bullying e a percepção dos estudantes MatoGrossenses. Research, Society and Development, 9(7), 1-21. http://dx.doi.org/10.33448/rsd-v9i7.3865.

Ottoni, I. C., Domene, S. M. Á., \& Bandoni, D. H. (2019). Educação Alimentar e Nutricional Em Escolas: Uma Visão Do Brasil. Demetra: Alimentação, Nutrição \& Saúde, 14, e38748. https://doi.org/10.12957/demetra.2019.38748.

Peixinho, A. M. L. (2013). A trajetória do Programa Nacional de Alimentação Escolar no período de 2003-2010: relato do gestor nacional. Ciência \& Saúde Coletiva, 18(4), 909-916. https://doi.org/10.1590/s1413-81232013000400002.

Pérez Luňo, A.H. (2001). Derechos humanos, estado de derecho y constitución. Tecnos.

Prandi, R. (2001). Mitologia dos orixás. (1 ed.p.48).:Companhia das letras

Roché, S.(2000). Tolérance Zero? Incivilités et insecurités. Éditions Odile Jacob.

Silva, E. O., Amparo-Santos, L., \& Dantas Soares, M. (2018). Alimentação escolar e constituição de identidades dos escolares: Da merenda para pobres ao direito à alimentação. Cadernos de Saude Publica, 34(4), 1-13. https://doi.org/10.1590/0102-311x00142617

Siqueira, R. L., Cotta, R. M. M., Ribeiro, R. de C. L., Sperandio, N., \& Priore, S. E. (2014). Análise da incorporação da perspectiva do direito humano à alimentação adequada no desenho institucional do programa nacional de alimentação escolar. Ciência \& Saúde Coletiva, 19(1), 301-310. https://doi.org/10.1590/1413-81232014191.2114

Tavares dos santos, J.V. \& Machado, E. M. (2019). A violência na escola e os dilemas do controle social. Rev. bras. Segur. pública, 13(2), p.106-125. https://doi.org/10.31060/rbsp.2019.v13.n2.1113

Unesco (2019). Violência escolar e bullying: relatório sobre a situação mundial. Unesco.

Vasconcelos,Y. L. (2015). Assédio moral nos ambientes corporativos. Cadernos EBAPE.BR, 13(4), 821 -851. https://bibliotecadigital.fgv.br/ojs/index.php/ca dernosebape/article/view/41446. 